\title{
EFFECT OF ULTRASONIC VIBRATION ON THE PARTICLE SIZE DISTRIBUTION OF HYDROXYAPATITE CHEMICALLY PRECIPITATED FROM EGGSHELLS
}

\author{
GREGORIO VARGAS*, JORGE LÓPEZ*, JORGE L. ACEVEDO*, JORGE \\ ROMERO**, JUAN MÉNDEZ* and MANUEL MÉNDEZ* \\ *CINVESTAV-IPN Unidad Saltillo, Apartado Postal 663, 25000 Saltillo, \\ Coahuila, México, Tel. 52 (84) 8810 19, Fax. 52 (84) 881300 \\ **CIQA, Apartado Postal 379, 25100 Saltillo, Coahuila, México, Tel. 52 (84) 15 \\ 18 62, Fax. 52 (84) 154804
}

\begin{abstract}
The effect of ultrasonic vibration on the particle size distribution of hydroxyapatite chemically precipitated from eggshells and $\mathrm{H}_{3} \mathrm{PO}_{4}$, or alternatively from calcium acetate and $\mathrm{Na}_{3} \mathrm{PO}_{4} \cdot 12 \mathrm{H}_{2} \mathrm{O}$, was evaluated. For the case of hydroxyapatite aqueous suspensions with $\mathrm{pH}>10$, with no particle-dispersing agent added, the average particle size decreased from 40 to $3 \mu \mathrm{m}$ in five minutes by employing an ultrasonic power of 61.75 watts and a frequency of $20 \mathrm{KHz}$.
\end{abstract}

\section{INTRODUCTION}

The shell of the domestic hen eggs is an abundant and cheap source of calcium carbonate that can be used to synthesize hydroxyapatite $\left[\mathrm{Ca}_{10}\left(\mathrm{PO}_{4}\right)(\mathrm{OH})_{2}\right]$ by employing techniques such as chemical precipitation ${ }^{1}$, hydrothermal exchange ${ }^{1}$ or solid phase reaction $^{2}$. Nearly $11 \%$ of the total weight of an egg corresponds to the eggshell ${ }^{2}$. This contains approximately $94 \mathrm{wt} \% \mathrm{CaCO}_{3}$ (calcite), $1 \mathrm{wt} \% \mathrm{MgCO}_{3}, 1 \mathrm{wt} \% \mathrm{Ca}_{3}\left(\mathrm{PO}_{4}\right)_{2}, 3 \mathrm{wt} \%$ protein and $1 \mathrm{wt} \%$ fat, with traces of $\mathrm{Na}, \mathrm{K}, \mathrm{Zn}, \mathrm{Mn}, \mathrm{Fe}$ and $\mathrm{Cu}^{2}$. In the present work, hydroxyapatite was synthesized from powdered eggshells and phosphoric acid and alternatively from calcium acetate (obtained by dissolving the eggshells with acetic acid) and hydrated sodium phosphate. The effect of ultrasonic vibration on the particle size distribution (PSD) of hydroxyapatite synthesized under different experimental conditions was evaluated. The purpose of this study was to determine the optimal 
conditions for the production of hydroxyapatite with a PSD suitable for the preparation of suspensions used to obtain hydroxyapatite coatings by electrophoretic deposition.

\section{EXPERIMENTAL PROCEDURE}

In order to eliminate as much organic matter as possible, the eggshells were boiled five times in an aqueous solution of reagent grade hydrogen peroxide, rinsing in deionized water after each boiling cycle. After cleaning and drying the eggshells, these were milled in order to obtain a fine powder with a particle size smaller than $50 \mu \mathrm{m}$. Hydroxyapatite was chemically precipitated by using two different experimental procedures. In the first one, an aqueous solution of phosphoric acid (1M) was added dropwise to a vigorously and continuously stirred aqueous suspension prepared with the powdered eggshells. In the second experimental procedure, a similar aqueous suspension was reacted with reagent grade acetic acid to obtain an aqueous solution of calcium acetate, which was separated by filtration from the residual insoluble organic matter still contained in the eggshells. Then, the calcium acetate was precipitated and the residual acetic acid was eliminated by evaporation. After redissolving the calcium acetate in deionized water, it was reacted with an aqueous solution of sodium phosphate $\left[\mathrm{Na}_{3} \mathrm{PO}_{4} \cdot 12 \mathrm{H}_{2} \mathrm{O}\right]$ under a vigorous and continuous stirring, producing hydroxyapatite and an aqueous solution of sodium acetate. In all cases the required relative volumes of the chemical reactants were determined, according to the volume capacity of the chemical reactor (one liter), aiming for a final $\mathrm{Ca} / \mathrm{P}$ molar ratio of 1.67 in the resulting hydroxyapatite aqueous suspensions. The hydroxyapatite synthesis was carried out under an atmosphere of still ambient air at room temperature. Both temperature and $\mathrm{pH}$ were continuously monitored but not controlled. Each one of the hydroxyapatite aqueous suspensions obtained was divided into four equal parts, one of which was stored as a reserve sample. The rest of the samples were subjected to an ultrasonic vibration for five minutes, using ultrasonic powers of $23.75,42.75$ and 61.75 watts, at a frequency of $20 \mathrm{KHz}$. In order to stabilize the hydroxyapatite aqueous suspensions, four commercially available particle-dispersing agents were tried in a proportion of $1 \mathrm{wt} \%$. These were polyvinyl alcohol (PVA), polyacrylic acid (PAA), sodium polyacrylate (Darvan 811) and polyvinylpyrrolidone (PVP). The particle size distribution was 
determined for each one of the precipitates using a Coulter LS 100Q particle size analyzer. Measurements of $\mathrm{z}$ potential were carried out as a function of $\mathrm{pH}$ for all four particle-dispersing agents employed, using a Model 501Lazer Zee Meter apparatus. For these measurements, the aqueous suspension $\mathrm{pH}$ was adjusted between 6 and 11 by adding a $\mathrm{NaOH}$ diluted aqueous solution. Since the isoelectric point (IEP) of hydroxyapatite can be found ${ }^{3,4}$ at $\mathrm{pH}$ values between 4 and 7 , acidic $\mathrm{pH}$ values were not considered. This allowed to avoid the transformation of hydroxyapatite into another calcium phosphate species under acidic conditions. The chemical composition of the precipitates was verified by X-Ray Diffraction (XRD), using a Philips X-Pert MPD $\mathrm{XRD}$, and by infrared spectroscopy, using an Impact 420 Nicolet FTIR.

\section{RESULTS AND DISCUSSION}

The $\mathrm{z}$ potential plays an important role as a measure of the stability of colloidal suspensions. It is well known ${ }^{3}$ that suspensions with $\mathrm{pH}$ values close to the IEP show a strong tendency to flocculate because in this case the repulsive forces may not be sufficient to overcome the Van der Waals attraction between the particles. Thus, a suspension having a $\mathrm{pH}$ significantly different to the IEP will be stable. Figure 1 shows the results obtained from the $\mathrm{z}$ potential measurements made as a function of $\mathrm{pH}$ for the electrolytes tested in this work to stabilize the hydroxyapatite suspensions.

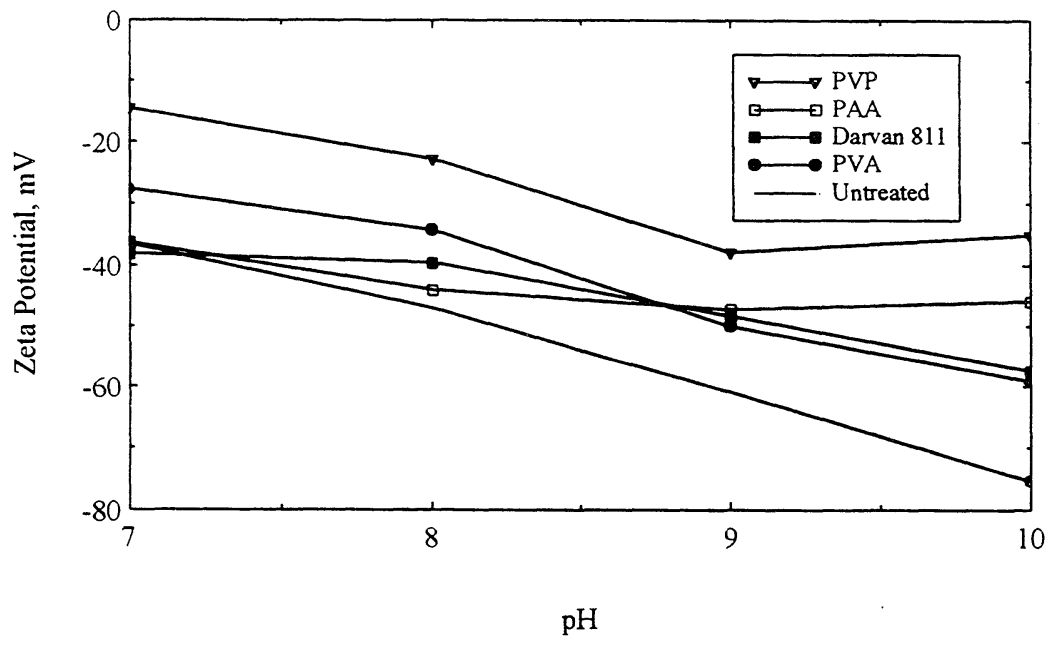

FIGURE 1. $\mathrm{Z}$ potential measurements as a function of $\mathrm{pH}$. 
As can be noticed from Figure 1, the z potential decreased substantially below the IEP with increasing $\mathrm{pH}$ for all particle-dispersing agents employed. The largest decrease in $\mathrm{z}$ potential corresponded, however, to the hydroxyapatite suspensions without the addition of a particle-dispersing agent. This suggested that the presence of $\mathrm{Na}^{+}$ions from the added $\mathrm{NaOH}$ played a key role in the stabilization of the suspensions by increasing the repulsive forces between the hydroxyapatite particles, especially for the case of the alkaline solutions. It has been reported ${ }^{4}$ that $\mathrm{Na}^{+}$ions can preferentially adsorb onto the surface of many particulated ceramics, leading to a superficial electrostatic charge. This is the reason why many commercially available particledispersing agents contain sodium. For instance, Darvan 811 , which was one of the particle-dispersing agents producing $\mathrm{z}$ potential values similar to those corresponding to the hydroxyapatite suspensions with no additives (Figure 1), also contains sodium.

Figure 2 shows the particle size distribution corresponding to hydroxyapatite precipitated via chemical reaction between the eggshells and phosphoric acid. As can be noticed, the average particle size decreased from approximately $20 \mu \mathrm{m}$ without ultrasonic vibration to $10 \mu \mathrm{m}$ when an ultrasonic power of 61.75 watts was employed. Figure 3 shows the corresponding particle size distribution for hydroxyapatite precipitated from calcium acetate and hydrated sodium phosphate. A similar decrease in the average particle size from 40 to $3 \mu \mathrm{m}$ was observed. This results can be explained based on the known fact $^{5}$ that exposing a liquid to a progressively higher ultrasonic power results in the formation of small vapor bubbles, called cavities, when certain energy threshold is exceeded. These cavities form everywhere within the liquid and collapse violently, which results in the application of mechanical forces upon the aggregated particles. If such forces are strong enough, they can break apart weakly bonded particles, particularly those joined by Van der Waals forces. In all cases, the particle size distribution was redetermined 48 hours after the application of the ultrasonic vibration to the hydroxyapatite aqueous suspensions. This was done in order to verify that the suspensions remained stable with increasing time. However, this was observed to be so only for the case of hydroxyapatite precipitated from calcium acetate and sodium phosphate, for which the finest particle size was obtained. Probably in this case the presence of $\mathrm{Na}^{+}$ions from the sodium acetate aqueous solution helped to stabilize the hydroxyapatite suspensions. For the case of hydroxyapatite precipitated 
from eggshells and phosphoric acid, a rapid sedimentation was observed, which can be attributed to a larger particle size corresponding to these suspensions.

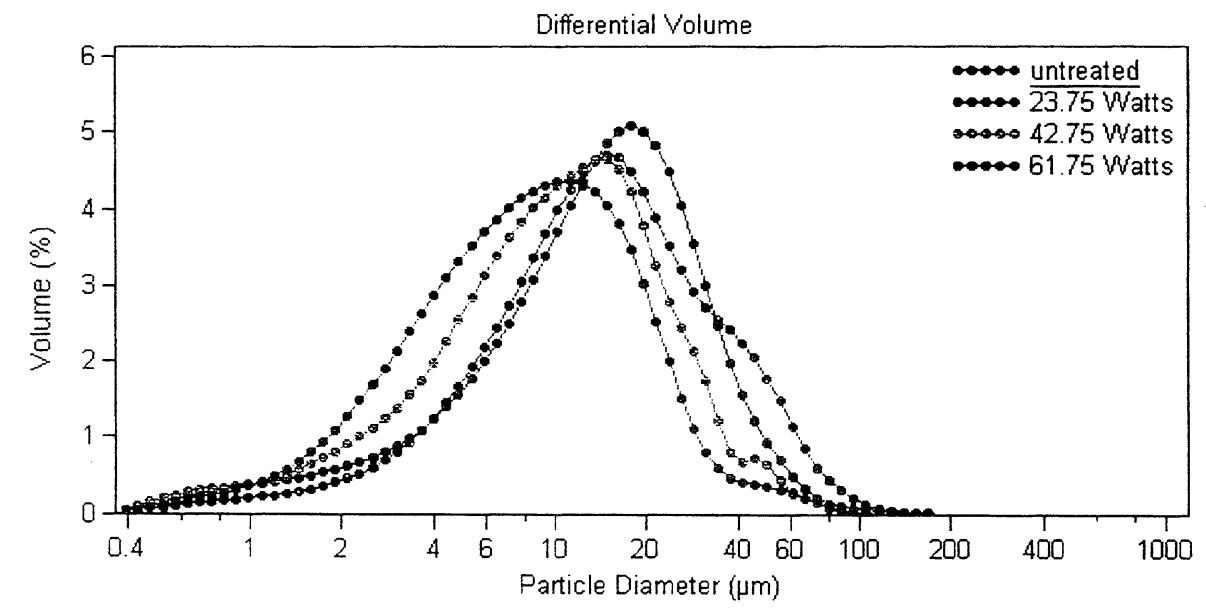

FIGURE 2. Particle size distribution for hydroxyapatite chemically precipitated from eggshells and phosphoric acid.

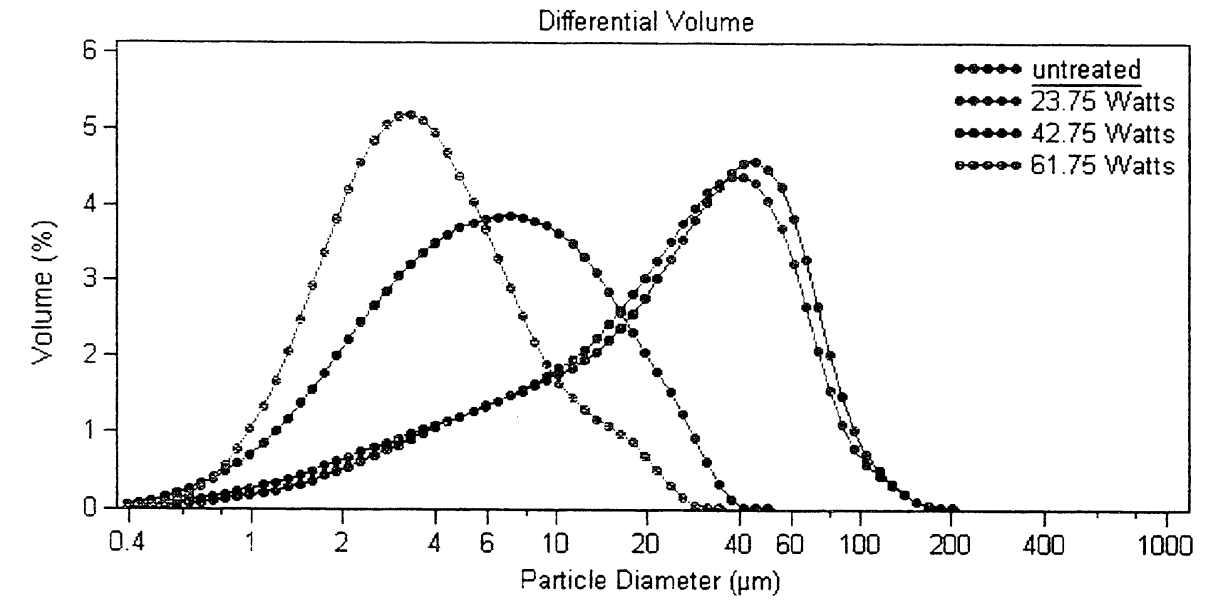

FIGURE 3. Particle size distribution for hydroxyapatite chemically precipitated from calcium acetate and hydrated sodium phosphate. 


\section{SUMMARY}

Hydroxyapatite was chemically. precipitated from powdered eggshells and $\mathrm{H}_{3} \mathrm{PO}_{4}$, or alternatively from calcium acetate (obtained by dissolving the eggshells with acetic acid) and $\mathrm{Na}_{3} \mathrm{PO}_{4} \cdot 12 \mathrm{H}_{2} \mathrm{O}$. The effect of ultrasonic vibration on the particle size distribution of the synthesized hydroxyapatite was evaluated. The average particle size decreased from 40 to $3 \mu \mathrm{m}$ in five minutes by using an ultrasonic power of 61.75 watts and a frequency of $20 \mathrm{KHz}$ for the case of hydroxyapatite aqueous suspensions with $\mathrm{pH}>10$, without the use of a particle-dispersing agent.

\section{ACKNOWLEDGEMENTS}

Thanks are due to Juan A. Gonzalez for his invaluable technical assistance.

\section{REFERENCES}

1 C.C. Berndt, G.N. Haddad, A.J.D. Farmer, K.A. Gross, Mater Forum, 14, 161 (1990).

2 R. Curiel, B.Sc. Tesis, Facultad de Química, Universidad Nacional Autónoma de México (1998).

3 M.N. Rahaman, Ceramic Processing and Sintering, (Marcel Dekker Inc., New York, 1995), Chap.4. pp.146-200.

4 J.S. Reed, Principles of Ceramic Processing, (Wiley Interscience, New York, 1994), Chap. 10.pp.150-168.

5 T.A. Ring, Fundamentals of Ceramic Powder Processing and Synthesis, (Academic Press, 1996), Chap.9.pp.375-378. 